\title{
Coralligenous reefs state along anthropized coasts: Application and validation of the COARSE index, based on a rapid visual assessment (RVA) approach
}

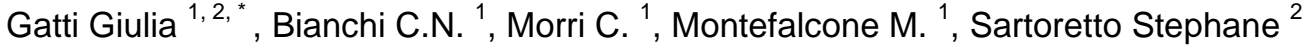 \\ ${ }^{1}$ DISTAV, Department of Earth, Environment and Life Science, University of Genoa, corso Europa 26, \\ 16132 Genoa, Italy \\ ${ }^{2}$ IFREMER, Zone Portuaire de Brégaillon, 83500 La Seyne-sur-mer, France \\ * Corresponding author : Giulia Gatti, Tel.: +39 0103538584. ; email address : gatti.giulia25@gmail.com
}

\begin{abstract}
:
A rapid visual assessment (RVA) approach for the characterization and assessment of the integrity of coralligenous reefs was applied in 21 stations subjected to different levels of anthropogenic pressure, along the French Mediterranean coasts. The reefs were characterized from both the geomorphologic and bionomic (biotic cover, conspicuous species richness, canopy-forming species, etc.) points of view, and their health status was estimated through the COARSE (COralligenous Assessment by ReefScape Estimate) index. The sensitivity of the COARSE index and the robustness of the RVA approach to observer biases were analyzed. Results showed that most coralligenous reefs were characterized by (sub) vertical cliffs or platforms with variable slope, usually dominated by biotic facies with Paramuricea clavata and/or Eunicella cavolini in healthy stations, or by algal associations or facies of impoverishment in the most impacted situations. The overall quality scores of the COARSE index generally reflected the putative level of stress of the sampling stations; differences due to observer biases resulted negligible. Coupling the RVA approach with the COARSE index proved an effective protocol for both the characterization and the evaluation of coralligenous reefs: the former is achieved by the analysis of the whole complexity of this habitat, the latter provides for the first time an indication of sea-floor integrity, differently from previous indices that aim at estimating water quality.
\end{abstract}

Keywords: Coralligenous reefs, Rapid visual assessment, Sea-floor integrity, Visual estimation, COARSE index, Mediterranean Sea 


\section{Introduction}

The endemic biogenic reefs known as "coralligenous" (Ballesteros, 2006) represent the second pole of species diversity in the Mediterranean Sea, after the Posidonia oceanica meadows (Boudouresque, 2004). Nevertheless, the complex structure of coralligenous reefs (Pérès and Picard, 1964; Ros et al., 1985 ) and their highly diverse composition (Laubier, 1966) suggest that they probably host more species than any other Mediterranean habitat, but to date the number of studies dealing with their biodiversity is still low (Ballesteros, 2006). Estimates on the number of invertebrates (Laubier, 1966; Ros et al., 1984) and macroalgae (Boudouresque, 1973) exist, while information on fish is scarce (Spanier et al., 1989; Harmelin, 1990; Guidetti et al., 2002). Anyway, a first cumulative and still conservative estimate of the total number of coralligenous species is given by Ballesteros (2006) and accounts for about 1670 species.

Despite the obvious importance of coralligenous reefs, the European Directives in the field of environmental protection rarely refer to them directly. The Habitat Directive (HD, 92/43/EEC) incorporates "reefs", in the widest sense, in the list of habitats of community interest (Annex I). As a consequence, coralligenous reefs have been automatically included in the network of Natura 2000 (Council European Communities, 1992). On the contrary, the Water Framework Directive (WFD, 2000/60/EC) mentions the assessment of composition and abundance of the benthic flora and fauna only as a means for the monitoring of the ecological status of marine waters, and this probably addressed researchers to some "easier-to-study" and best known benthic habitats, like soft bottoms (Borja et al., 2000; Simboura and Zenetos, 2002; Rosenberg et al., 2004; Muxika et al., 2007), upper infralittoral algal belts (Orfanidis et al., 2001; Ballesteros et al., 2007), or seagrass meadows (Romero et al., 2007; Gobert et al., 2009; Lopez y Royo et al., 2009). Despite the Protocol for Special Protected Areas (SPA/BIO) of the Barcelona Convention for the conservation of Mediterranean biodiversity (1995) directly considered coralligenous reefs among the habitats that need a rigorous protection, it was only in 2008 that the , Action plan for the conservation of coralligenous and other calcareous concretions in the Mediterranean Sea eee was developed (UNEP-MAP-RAC/SPA, 2008). The action plan encouraged the conservation of coralligenous reefs by the establishment of marine protected areas and emphasized the need for standardized monitoring programs: this new way of thinking allowed pinpointing the gaps in the knowledge about geographical and bathymetrical distribution, taxonomy, functioning and dynamics of coralligenous communities. In the same year, the Marine Strategy Framework Directive (MSFD, 2008/56/EC) introduced the concept of "sea-floor integrity" for the assessment of the status of marine environment; among others, biogenic structures, such as the Mediterranean coralligenous reefs, should be adopted as indicators of sea-floor integrity (Rice et al., 2012).

Usually, to assess the Ecological Status (ES) of a habitat it is necessary to follow three steps (Borja et al., 2012): i) definition of a reference condition or, where not possible, some environmental targets for 
the good status of the habitat; ii) computation of an indicator for the reference condition for the considered habitat, in order to obtain an Ecological Quality Ratio (EQR) (sensu WFD); iii) conversion of the EQR into an ES value. Concerning coralligenous reefs, the paucity of knowledge, coupled with the diffused problem of the sliding (or shifting) baselines (Al-Abdulrazzak et al., 2012), does not allow to define general reference conditions or to set targets using "traditional" methods (see Borja et al., 2012). A possible solution could be to provide a large-scale current baseline for future evaluations of the habitat state, as did Sala et al. (2012) for shallow rocky reefs.

Coralligenous reefs may encompass a high number of different biogenic formations (Sarà, 1969), and their specific composition (Laborel, 1960, 1961; Antoniadou and Chintiroglu, 2005), structure and depth range (Ballesteros, 2006) can vary at both geographical (Virgilio et al., 2006; Casellato and Stefanon, 2008) and local scale (Ferdeghini et al., 2000) according to the different environmental factors and to the geomorphology of the area (Ponti et al., 2011a). This extreme variability and the operational restrictions imposed by scuba diving (Parravicini et al., 2010) when working at depths at which coralligenous reefs develop, limited the number of studies aimed at assessing their health status. The Ecological Status of Coralligenous Assemblages index (ESCA) (Cecchi and Piazzi, 2010) and the Coralligenous Assemblage Index (CAI) (Deter et al., 2012) adopt coralligenous reefs as an indicator of ES of coastal waters, according to the WFD; both indices are based on photographic sampling and the subsequent analysis of images to provide data on the composition and abundance of species. With respect to photographic samples, visual techniques have several advantages (e.g., flexible resolution, detection of organisms hardly visible on photographs, possibility of measuring and sampling, etc.) (Parravicini et al., 2009) and have therefore proven efficient in several underwater monitoring protocols, such as Reef Check (Hogdson, 1999). Differently from the existing approaches, the COARSE (COralligenous Assessment by ReefScape Estimation) index proposed in the present paper uses SCUBA diving observations and measurements to gather data useful to evaluate the state of coralligenous reefs as an indicator of sea-floor integrity rather than coastal water quality. In addition to biotic cover and conspicuous species richness, the COARSE index takes into account the three-dimensional structure of coralligenous reefs, currently considered essential and complementary for the evaluation of the health status of communities (Alvarez-Filip et al., 2011; Ar Gall and Le Daff, 2014). The COARSE index is based on the Rapid Visual Assessment (RVA) approach proposed by Gatti et al. (2012). The wide-scale application of the RVA allowed some shortcomings emerging: the original protocol, therefore, has been revised to get a more efficient evaluation of coralligenous reefs state.

The aim of the present paper is to test the effectiveness of the COARSE index and its sensitivity to different levels of human pressure, which is an essential characteristic for a quality index. Since it is based on a direct visual method, the index may suffer the consequences of the variability between observers that can affect both the visual estimations of percent cover (Meese and Tomich, 1992) and 
the correct identification of species (Thompson and Mapstone, 1997). Thus, we also tested the robustness of the RVA approach to the observer bias. Finally, a new formula for the computation of the overall quality scores of the index is proposed to better reflect the health state of coralligenous reefs.

\section{Materials and methods}

\subsection{Study area and field work}

The study area is located along the French Mediterranean coasts, around the cities of Toulon, La Ciotat and Marseille, in the Provence-Alpes-Côte-d"Azur (PACA) region (Fig. 1). The area is characterized by high population density, which determines the presence, along an $80 \mathrm{~km}$ long coast, of four stations for sewage treatment and discharge, for a total capacity of 2.3 millions of equivalent inhabitants. During the summer, this number increases because of the touristic presence, concurrently with the intensification of all the marine activities (e.g. recreational diving, yachting, etc.) usually practiced during the whole year. The local fishery completes the picture of a region where the coastal marine environment is strongly affected by human presence.

The study area is characterized by high rocky shores mainly composed of limestone in the zone of Marseille, conglomerates at La Ciotat, and phylades (siliceous rocks) near Toulon. Between the surface and the continental shelf, the area is dominated by the Liguro-Provencal current, which normally flows westwards; the coastal circulation is also constrained by two dominant winds: the north-western (upwelling favorable) and the south-eastern (downwelling favorable) (Pairaud et al., 2011). Locally (e.g. around Marseilles), the upwelling induces a decrease of temperature reaching more than $5^{\circ} \mathrm{C}$ (Millot, 1990).

A total of 21 sampling stations have been chosen in the study area (Fig. 1). Using expert judgments (Burgman et al., 2011), three levels of human pressures were identified and the sampling stations were listed according to the level of pressure they are subjected to:

- High pressure, mainly due to sewage treatment stations outfalls: Ile Plane Nord (8 in Fig. 1), Figuerolle (12), Sêche des Pêcheurs West (17), Large Oursinière (20);

- Moderate pressure, mainly due to scuba diving, fishery, sediment resuspension or small effect of sewage treatment stations outfalls: Méjean (1), Large Niolon (2), Fromages (6), Imperial du Milieu (9), Ile Plane South (10), Bec de l“Aigle West (13), Pierre du Levant (16), Formigue (21);

- Low pressure: Tiboulen (3), Ile du Planier (4), Cap Caveau (5), Moyade (7), Sêche des Pêcheurs East (18), Morgiou (11), Bec de l“Aigle East (14), Les Rosiers (15), Les Deux Frères (19). 
Sampling activities took place during summer 2013. In each station, three replicated visual surveys at constant depth were carried out by a single SCUBA diver (hereafter called $\mathrm{O}_{1}$ ), for a total of 63 replicates of about $1.5 \mathrm{~m}^{2}$ each.

For each station, a geomorphologic characterization was obtained in situ by considering the most frequent "morphotypes" that may allow the development of coralligenous reefs, i.e. shoals, outcrops, cliffs, landslide deposits, and detritic bottoms. The following mesologic parameters were also measured in each replicate: depth, elevation from the bottom, slope, and exposure of the substrate. As coralligenous assemblages show a stratified structure, for each replicate bionomic data were collected separately for three distinct layers: 1) basal layer, constituted by encrusting or with limited ( $<1 \mathrm{~cm}$ ) vertical growth organisms; 2$)$ intermediate layer, composed by organisms with moderate (1 $\mathrm{cm}$ to $10 \mathrm{~cm}$ ) vertical growth; 3$)$ upper layer, characterized by organisms with considerable $(>10 \mathrm{~cm})$ vertical growth.

In the basal layer, the percent cover of five benthic categories (hereafter called BCs) were visually estimated: encrusting calcified Rhodophyta (ECR), non-calcified encrusting algae (NCEA), encrusting animals (EA), turf-forming algae and sediment (TURF/SED). A semi-quantitative assessment of boring species marks (e.g. clionid papillae and bivalve holes) was performed through the assignation of three classes of abundance (common, occasional, absent). Finally, thickness of the calcareous concretion was measured in millimetres with a handheld penetrometer.

In the intermediate layer, a list of conspicuous species was filled in and, in addition to the original protocol (Gatti et al., 2012), six photographs were randomly shot without a frame over the sampled surface, to integrate the list visually compiled underwater.

In the upper layer, the percent cover of each species and the percentage of necrosis (even if covered by epibionts) of each population were visually estimated. Finally, for each species, the maximum height of the tallest specimen was measured. Table 1 summarizes all data collected to obtain the geomorphologic, mesologic and bionomic characterization of coralligenous reefs. For further details about the method, see Gatti et al. (2012).

In order to assess the sensitivity of the RVA approach, and therefore of the COARSE index, to observer biases, in eight stations a second observer (hereafter called $\mathrm{O}_{2}$ ) applied the protocol on the same surfaces, in independent dives.

In addition to the standard protocol illustrated above, four $60 \mathrm{~cm} \times 40 \mathrm{~cm}$ photographs for each RVA replicate were shot on the same surfaces observed by the SCUBA divers, in order to compare the visual percent cover estimation of basal layer"es BCs with the percent cover assessed by the analysis of images.

Finally, in order to verify if the experience of the observers could influence the visual estimation of BCs percent cover, in two stations data were collected by four divers: $\mathrm{O}_{1}$ and $\mathrm{O}_{2}$, which have a good experience in visual estimations and identification of benthic species, and $\mathrm{O}_{3}$ and $\mathrm{O}_{4}$, which have no 
experience. A pre-sampling briefing gave them the essential information for the identification of the BCs.

\subsection{Data management}

\subsubsection{Characterization and quality assessment}

From the quali-quantitative composition of the assemblages, the dominant species allowed for the definition of the habitat types. In Gatti et al. (2012), habitat types were identified according to the European Nature Information System (EuNIS) codification (Davies et al., 2004). Here the codification approach was maintained where possible, but in case of facies or associations that were not present in EuNIS list, the habitat type was identified by the name of the dominant species.

As three main community layers are usually recognized in coralligenous reefs (basal, intermediate and upper), quality was assessed for each layer individually on the basis of the different descriptors. A total of nine descriptors, three for each layer, was used. The criteria adopted to assign quality scores to each descriptor, for each replicate, are described below and summarized in Table 2.

Basal layer.

i) BCs percent cover - score 1 was assigned to TURF/SED because they may play a negative role in the bioconstructional processes; score 2 to NCEA and EA, for their role in substrate protection; score 3 to ECR, the main active producers of calcareous substrate. The formula (cover*score)/100 was applied to each BCs, and results were summed up to obtain the quality score of the descriptor. A minor change compared to Gatti et al. (2012) concerned the attribution of quality scores to TURF and SED (which were, respectively, equal to 1.5 and 1) and is discussed in Section 4.3.

ii) Thickness and consistency of calcareous layer - score 1 was assigned when penetration was null, meaning absent or no more active bioconstruction; 2 when the penetration was centimetric, suggesting unconsolidated bioconstruction; 3 when penetration was millimetric, which indicates active bioconstruction and a compact calcareous layer.

iii) Borer marks - borers may weaken the calcareous substrate, therefore score 1 was assigned when borers were common, 2 when occasional and 3 when absent.

For the intermediate layer, three descriptors were obtained from the list of conspicuous species compiled underwater, enriched with the additional species, if any, detected thanks to the photographs collected.

iv) Species richness $(S R)$ - preliminary investigations showed that the minimum number of species detected in non-impacted areas was about 8 , then score 1 was arbitrarily assigned when $\mathrm{SR}<5$, score 2 when $5 \leq \mathrm{SR}<8$, score 3 when $\mathrm{SR}>8$.

v) Erect calcified organisms (ECO) - erect calcified invertebrates may give a consistent contribution among coralligenous bioconstructors (Hong, 1982), so the number of species of such organisms was considered; as preliminary investigations showed that the minimum number of ECO observed in non- 
impacted areas was about 3 , then score 1 was arbitrarily assigned when $E C O \leq 1$, score 2 when $1<\mathrm{ECO} \leq 3$, score 3 when $\mathrm{ECO}>3$. This descriptor replace, with minor changes, the descriptor "Erect calcified bryozoans" (ECB) originally adopted in Gatti et al. (2012); this variation is discussed in Section 4.3.

vi) Sensitivity of bryozoans - bryozoans are considered sensitive to pollution (Hong, 1983), but species respond differently to such a pressure: Perez et al. (2002) suggested that Myriapora truncata is the less sensitive, being often the only bryozoan present in highly degraded situations, while Smittina cervicornis and Reteporella grimaldii, preferring the less polluted environments, are the most sensitive; other two species, namely Pentapora fascialis and Adeonella calveti, were indicated as intermediate between the two groups above. Therefore, considering only the most sensitive among the species detected in each replicate, score 1 was assigned to $M$. truncata, score 2 to $P$. fascialis and $A$. calveti, and score 3 to $S$. cervicornis and R. grimaldii. This descriptor replaces the "Seasonal-perennial species ratio" originally employed by Gatti et al. (2012); also this variation is discussed in Section 4.3. Upper layer.

vii) Total cover of species - according to Pérès and Picard (1964), score 1 was assigned when cover $<5 \%$, score 2 when $5 \% \leq$ cover $\leq 25 \%$, and score 3 when cover $>25 \%$.

viii) Maximum height $(\mathrm{MH})$ - the maximum height of the tallest species was compared to the maximum height value available in literature $(\mathrm{LMH})$ for that species. Then score 1 was arbitrarily assigned when $\mathrm{MH}<1 / 3 \mathrm{LMH}$, score 2 when $1 / 3 \mathrm{LMH} \leq \mathrm{MH} \leq 2 / 3 \mathrm{LMH}$, score 3 when $\mathrm{MH}>2 / 3 \mathrm{LMH}$. ix) Necrosis $(N)$ - considering the percentage of necrosis of organisms, even when covered by epibionts, over the whole populations, score 1 was assigned when $\mathrm{N}>75 \%$, score 2 when $10 \% \leq \mathrm{N} \leq 75 \%$, score 3 when $\mathrm{N}<10 \%$.

The mean value among replicates ${ }^{e e}$ scores gave the final score for each descriptor. Then, in order to get the COARSE index quality score for each layer $\left(\mathrm{Q}_{\mathrm{L}}\right)$, starting from descriptors scores, the formula [1] formerly described in Gatti et al. (2012) and inspired by the one adopted by Bianchi et al. (2012) was applied:

$$
\mathrm{Q}_{\mathrm{L}}=\left(\mathrm{X}_{\mathrm{L}} \times \mathrm{Y}_{\mathrm{L}} \times \mathrm{Z}_{\mathrm{L}}\right) \times k^{(1-n)}
$$

The harmonic mean among the three $\mathrm{Q}_{L} \mathrm{~s}$ (formula [2]) was then used to calculate an overall quality score $\left(\mathrm{Q}_{\mathrm{O}}\right)$ for each station:

$$
\mathrm{Q}_{\mathrm{O}}=n /\left(1 / \mathrm{Q}_{\mathrm{BL}}+1 / \mathrm{Q}_{\mathrm{IL}}+1 / \mathrm{Q}_{\mathrm{UL}}\right)
$$

where $n$ is the number of layers and $\mathrm{Q}_{\mathrm{BL}}, \mathrm{Q}_{\mathrm{IL}}$ and $\mathrm{Q}_{\mathrm{UL}}$ are the quality scores of basal, intermediate and upper layer, respectively.

Finally, in order to obtain a classification of quality, for both $\mathrm{Q}_{\mathrm{L}}$ and $\mathrm{Q}_{\mathrm{O}}$, only three classes were considered: Bad when $\mathrm{Q}_{\mathrm{L}}$ or $\mathrm{Q}_{\mathrm{O}} \leq 1$, Moderate when $1<\mathrm{Q}_{\mathrm{L}}$ or $\mathrm{Q}_{\mathrm{O}} \leq 2$, Good when $2<\mathrm{Q}_{\mathrm{L}}$ or $\mathrm{Q}_{\mathrm{O}} \leq 3$. Since the subdivision in classes of quality was changed as compared to what described in Gatti et al. (2012), in Section 4.3 such change is discussed. 
To see whether the COARSE index is adequately sensitive to anthropogenic pressure, 1-way analyses of variance (ANOVAs) were applied to $\mathrm{Q}_{\mathrm{O}}, \mathrm{Q}_{\mathrm{BL}}, \mathrm{Q}_{\mathrm{IL}}$ and $\mathrm{Q}_{\mathrm{UL}}$, grouped according to three level of pressure identified: low (LP), moderate (MP), and high pressure (HP).

\subsubsection{Robustness to observer biases}

For the analysis of photos $40 \mathrm{~cm} \times 60 \mathrm{~cm}$, the percent cover of BCs (ECR, NCEA, EA, TURF/SED) was visually estimated with the help of a grid (200 cells) superimposed on each image.

Cluster Analysis, based on Euclidean Distances and average linkage, was performed on multivariate descriptors (BCs percent cover) in order to compare: i) the visual estimates obtained underwater by $\mathrm{O}_{1}$ and $\mathrm{O}_{2}$ (mean values) and the percent cover obtained by the analysis of the photographs; ii) the visual underwater estimations of $\mathrm{O}_{1}$ and $\mathrm{O}_{2}$; iii) the visual estimations of observers with experience $\left(\mathrm{O}_{1}, \mathrm{O}_{2}\right)$ and those of observers with no experience $\left(\mathrm{O}_{3}, \mathrm{O}_{4}\right)$.

Univariate data (thickness and consistency of calcareous layer and borer marks for the basal layer; species richness, erect calcified organisms, and sensitivity of bryozoans for the intermediate layer; total cover of species, maximum height, and necrosis for the upper layer) were analyzed by paired Studentes $t$ tests in order to determine the differences, if any, between data collected underwater by $\mathrm{O}_{1}$ and $\mathrm{O}_{2}$.

\section{Results}

\subsection{Characterization and quality assessment}

The geomorphologic and mesologic characterization showed that the most frequent (15 stations) morphotypes were cliffs and platforms with variable slope, at depths between 28.7 and $39.4 \mathrm{~m}$. In most cases the EuNIS habitat "Mediterranean coralligenous communities moderately exposed to hydrodynamic action" (code A4.26) was identified, and the facies with Paramuricea clavata (code A4.26B) or the facies with Eunicella cavolini (code A4.269), sometimes coexisting, were the most common. However, two stations, one belonging to the high pressured (station 8) and one to the moderate pressured (station 2) situations, were characterized by a so-called "facies of impoverishment", which showed the vestiges of ancient populations of gorgonians. The outcrop morphotype, less represented in the study area (6 stations), was located between 26.4 and $34.5 \mathrm{~m}$ of depth and was generally characterized by associations of sciaphilic (Flabellia petiolata, Halimeda tuna) or hemiphotophilic (Codium bursa, Codium coralloides) green algae and only in one case by a habitat type codified in the EuNIS list, i.e. the association with $F$. petiolata and Peyssonnelia squamaria (code A3.23J), which belongs to the habitat "Mediterranean communities of infralittoral algae moderately exposed to wave action" (code A3.23). The only exception was represented by the station 15 , where the vertical southern wall of the outcrop was dominated by a facies with $P$. clavata (code A4.26B). A synopsis of all stations is summarized in Table 3. 
Layer's quality scores $\left(\mathrm{Q}_{\mathrm{L}}\right)$ showed high variability both within and among stations (Fig. 2). In stations characterized by high levels of pressure, the basal layer always exhibited bad quality $\left(\mathrm{Q}_{\mathrm{BL}} \leq 1\right)$, except for station $20\left(\mathrm{Q}_{\mathrm{BL}}=1.1\right)$, the intermediate layer scored lower than 1 with the exception of station $8\left(\mathrm{Q}_{\mathrm{IL}}=1.4\right)$, while the upper layer always exhibited $\mathrm{Q}_{\mathrm{UL}} \leq 1$.

In stations subjected to moderate pressure, the basal layer exhibited bad quality in one case (station 6 , $\left.\mathrm{Q}_{\mathrm{BL}}=0.8\right)$, while all other stations exhibited a moderate quality $\left(1.1>\mathrm{Q}_{\mathrm{BL}} \leq 2\right)$; the intermediate layer indicated a moderate quality in three out of the eight stations (1,10 and 16) and a good quality score $\left(\mathrm{Q}_{\mathrm{IL}}>2\right)$ in the remaining ones; the upper layer showed very variable situations: low quality in station 2, moderate in stations 1, 9, 13 and 21, and good quality in stations 6 and 10.

Finally, in low pressure stations, the basal layer exhibited bad quality only in station $14\left(\mathrm{Q}_{\mathrm{BL}}=0.7\right)$, good in station 4, 5 and 7 and moderate in all the others; intermediate and upper layers exhibited good quality in all stations except stations $14\left(\mathrm{Q}_{\mathrm{IL}}=1.7, \mathrm{Q}_{\mathrm{UL}}=1.7\right)$ and $15\left(\mathrm{Q}_{\mathrm{IL}}=0.6, \mathrm{Q}_{\mathrm{UL}}=0.7\right)$. The overall quality scores exhibited bad quality $\left(\mathrm{Q}_{\mathrm{O}} \leq 1\right)$ for stations $8,12,15,17$ and 20 , all subjected to high pressure with the exception of station 15 (low pressure). A moderate quality $\left(1.1>\mathrm{Q}_{\mathrm{O}} \leq 2\right)$ of coralligenous reefs was detected at stations $1,2,4,6,9,10,13,14$ and 16, all subjected to a moderate pressure whit the exception of station 14 (low pressure). Finally, good quality scores $\left(\mathrm{Q}_{0}>2\right)$ were assessed for stations $3,4,5,7,11,18$ and 19 , all subjected to low pressure.

Notwithstanding few exceptions, stations exhibited overall quality scores $\left(\mathrm{Q}_{0}\right)$ of COARSE index that reflected the levels of pressures they were subjected to (1-way Anova, $F=11.66, p=0.000$ ).

Similarly, the quality scores of each layer showed different according to the pressure level (1-way Anovas: $F=8.71, p=0.002$ for $\mathrm{Q}_{\mathrm{BL}} ; F=8.08, p=0.003$ for $\mathrm{Q}_{\mathrm{IL}} ; F=9.80, p=0.001$ for $\left.\mathrm{Q}_{\mathrm{UL}}\right)$.

\subsection{Robustness to observer biases}

Cluster analysis on the mean percent cover of $\mathrm{BCs}$ estimated by $\mathrm{O}_{1}$ and $\mathrm{O}_{2}$ and the $\mathrm{BCs}$ percent cover obtained by the analysis of the photographs revealed that the differences between operators and photos in the same station were lower than the differences between different stations (Fig 3a), so visual estimations were likely close to the actual cover of BCs. The only exception was station 6 , where the high cover by turf/sediment was underestimated by $\mathrm{O}_{2}$ in favor of encrusting corallines: this difference may be due, at least in part, to observations being conducted on surfaces with different slopes.

Concerning the comparisons between $\mathrm{O}_{1}$ and $\mathrm{O}_{2}$, the cluster analysis on $\mathrm{BCs}$ percent cover estimations showed differences between the two observers being lower than those among stations (Fig. 3b). Similarly, BCs percent cover estimations of observers with and without experience showed less important than the difference between the two sampling stations tested (Fig. 3c).

Paired Student's $t$ tests performed on univariate data (penetrometry, borer marks, number of species in the intermediate layer, total biotic cover of the upper layer, maximum height and necrosis) revealed no significant differences between the two experienced observers $\left(\mathrm{O}_{1}\right.$ and $\left.\mathrm{O}_{2}\right)$ in all cases (Table 4). 


\section{Discussion}

\subsection{Characterization and quality assessment}

Analyses of variance on all quality scores confirmed that the combined adoption of the COARSE index and the RVA approach is an efficient tool to assess sea-floor integrity of coralligenous reefs. The few exceptions, rather than simply being disappointing, may suggest the presence of some unexpected local factors that should have an important role in determining the composition and structure of the reefs, for which further investigations are needed. For example, the localization of the reefs and the geomorphologic characteristics of the seafloor can explain some situations where $Q_{O}$ resulted different from the expected. This is the case, for example, of station 2, subjected to moderate pressure, but located close to a sedimentation tank, implying that, during upwelling phenomena (Millot, 1990) or particular hydrodynamic situations, fine sediments are resuspended and may settle on benthic species, "naturally" affecting their development (Balata et al., 2007). Another factor that can play a role in conditioning the quality of coralligenous reefs, is the slope of the rocky substrate (Balata et al., 2005): station 6, affected by moderate pressure, showed altered only on moderately sloped surfaces, but was in good condition where the slope was steep enough to avoid the deposition of fine particles (roofs and protruding surfaces). Stations 14 and 15, which were classified as subjected to low pressures, showed a low value of $\mathrm{Q}_{0}$ : both stations are close to the coast and not so far from the water treatment plant of Figuerolle (see Fig. 1). One possible explication, therefore, is that, in particular meteorological and hydrodynamic situations, these stations can receive run-off from the land, the wastewater from Figuerolle, or even both, but no data regarding this area or these phenomena are available. The low quality of coralligenous reefs there may thus represent a warning to claim for specific monitoring activities.

In general, the assessment of coralligenous quality based on its structure and composition, as done by COARSE, does not seem to reflect primarily the quality of water, but confirms that coralligenous communities are more vulnerable to physical stress (Salomidi et al., 2012) like sedimentation (Balata et al., 2005, 2007; Roghi et al., 2010), rising temperature (Coma et al., 2009; Garrabou et al., 2009; Roghi et al., 2010; Wernberg et al., 2012), damages caused by SCUBA divers (Lloret et al., 2006; Di Franco et al., 2009), fishing activities (MacDonald et al., 1996; McClanahan and Sala, 1997), and boat anchoring (Lloret et al., 2008).

Notwithstanding their consistent response to pressure levels, layer's quality scores $\left(\mathrm{Q}_{\mathrm{L}}\right)$ exhibited high variability both within and among stations, confirming that layers can respond differently to the pressures they are subjected to (Bianchi et al., 2007; Ponti et al., 2011b). For this reason, when facing management issues, the overall quality score $\left(\mathrm{Q}_{\mathrm{O}}\right)$ must be considered only as a synthetic indication of the general state of coralligenous reefs, and the favorite option is to maintain the evaluation of the three layers separated, in order to clearly see what is necessary to act on (Gatti et al., 2012). 


\subsection{Robustness to observer biases}

The high similarity between the percent cover of BCs obtained through either visual estimations or the analysis of photographs confirmed that field observations are objective and reliable (Parravicini et al., 2009), with the advantage of getting data immediately, without further time-consuming analyses in the laboratory. In addition, percent cover estimations did not seem to be conditioned by the experience of the observer, in accordance with Meese and Tomich (1992). Similarly, the univariate measurements and counts as provided in the whole COARSE protocol were encouraging, since all data collected did not result affected by the observer bias. However, as depth, turbidity, enlightenment, cold and many other factors (e.g. restricted time during dives) sometimes can reduce the efficacy of underwater observations, taking some photographs is always recommended.

These results advocate for the application of the COARSE index over a wider scale with promising results.

\subsection{Variations in the RVA protocol}

The application over a larger number of stations and sites allowed improving the original RVA protocol first proposed by Gatti et al. (2012).

Concerning the intermediate layer, a substantial change consisted in the replacement of the descriptor

"Seasonal-perennial species ratio (S/P)", which was based on the ratio between the numbers of seasonal and perennial species aiming at measuring the stability of the reef community. The macrobenthic species of coralligenous assemblages exhibit very low to nil seasonality (Garrabou et al., 2002), minor seasonal differences being due to the pick of the productivity of some turf-forming, foliose or corticate-erect algae during summer (Ballesteros, 1991a, b; Piazzi et al., 2004). This determined that the value of the $\mathrm{S} / \mathrm{P}$ resulted always low, with a consequent high quality score also when the reefs were not really healthy, especially when few species were present. In addition, even if seasonal differences in coralligenous community composition are low, this limits the possibility of application of the protocol during the whole year and may produce different results when sampling in different seasons. Therefore, the S/P was replaced with the descriptor "Sensitivity of bryozoans (SB)", which aims to consider the different sensitivity to human impact of some species of erect bryozoans (Hong, 1983; Perez et al., 2002).

Another change concerning the intermediate layer consisted in the modification of the original descriptor "Erect calcified bryozoans ( ECB)". In fact, although it is true that erect calcified bryozoans are among the major animal calcifiers in coralligenous reefs, other erect invertebrates, such as some scleractinians, may play a non negligible role too (Hong, 1982). For this reason, the new descriptor "Erect calcified organisms (ECO)" accounts for all calcified organisms detected in the intermediate layer, in order to consider all possible contributors to the bioconstruction. 
As for the basal layer, a variation concerned the descriptor "BCs percent cover": the BCs "TURF" and "SED" were merged in a single category and they were assigned the same quality score (1), while in Gatti et al. (2012) the two groups were given the scores 1.5 and 1, respectively. This change was dictated by the necessity to consider the two BCs at the same "level". Turf forming algae often develop over sediment layers, with consequent difficulties in the assessment of the percent cover for the two BCs separately. In turn, turf carpets trap sediment (Airoldi et al., 1995) and have the same negative effects on coralligenous assemblages as sedimentation, excluding macroalgae by overgrowth and pre-emption (Piazzi et al., 2002) and impairing the recruitment of both fleshy macroalgae and invertebrates (Ballesteros et al., 1998).

A further change concerned the subdivision in classes of quality of the final $\mathrm{Q}_{\mathrm{L}} \mathrm{S}$ and $\mathrm{Q}_{\mathrm{O}} \mathrm{s}$. The fiveclasses criterion adopted by Gatti et al. (2012) was inspired by the existing classification of water ecological status suggested by the WFD; however, COARSE is not aimed at evaluating the ecological status of water bodies but at assessing sea-floor integrity as a descriptor of the status of the marine environment, according to the MSFD, for which no already defined classifications exist. Therefore, as quality scores of descriptors and layers are all based on a 1 to 3 scale, we decided to not introduce a further and artificial subdivision into five classes, and thus only three classes of quality (Bad, Moderate, Good) were adopted.

\section{Conclusions}

The COARSE index and the RVA approach showed to be robust to observer biases and sensitive to the different level of pressure identified in the study area, confirming to be an efficient tool for the assessment of coralligenous reefs integrity.

Indices already existing (Cecchi and Piazzi, 2010; Deter et al., 2012) are aimed to assess the environmental quality according to the WFD, therefore coralligenous communities are considered as indicators of the quality of coastal waters. Differently, COARSE uses a seascape approach to provide information about the structure and the composition of coralligenous reefs in order to assess the seafloor integrity (Gatti et al., 2012), which is one of the MSFD indicators of Good Environmental Status (Rice et al., 2012); in addition, the results of the present study did not encourage the use of coralligenous reef state as an indicator of water quality, since it seems to respond firstly to physical pressures (sedimentation, temperature, mechanical damages).

Anyway, the huge issue of setting the adequate reference conditions is still current. The comparison with pristine or minimally impacted areas is considered the best method for the assessment of the environmental status, as required by the MSFD (2008/56/EC); however, if we consider that the matter of sliding baselines is particularly relevant along the highly populated and urbanised coasts of the Mediterranean Sea (Sekovski et al., 2012; Parravicini et al., 2013), pristine areas could not be expected anymore (Jackson and Sala, 2001; Stachowitsch, 2003; Hobday, 2011; Tamburello et al., 2012). In this 
1 context, providing a current baseline (Sala et al., 2012) to which refer for future assessments of

2 coralligenous reefs integrity, is probably the best solution. The application of the COARSE index at

3 large scale could, therefore, provide a snapshot of the present-day situation of coralligenous reefs,

4 useful for future managing and conservation purposes. On-going research by our team is currently

5 applying it to other Mediterranean areas, different for latitude and stressor regime.

6

7

8 Acknowledgements

9 We wish to thank IFREMER-Centre de Méditerranée for supplying logistical facilities that allowed

10 carrying out the present work. In particular, we thank Christophe Ravel, Benoist De Vögue, Michelle

11 Brochen and Aurelie Vion for their precious support during the fieldwork. 


\section{References}

Airoldi, L., Rindi, F., Cinelli, F., 1995. Structure, seasonal dynamics and reproductive phenology of a filamentous turf assemblage on a sediment influenced, rocky subtidal shore. Bot. Mar. 38, $227-$ 273.

Al-Abdulrazzak, D., Naidoo, R., Palomares, M.L.D., Pauly, D., 2012. Gaining perspective on what we ve lost: the reliability of encoded anecdotes in historical ecology. PLoS One 7 (8), e43386.

Alvarez-Filip, L., Côté, I.M., Gil, J.A., Watkinson, A.R., Dulvy, N.K., 2011. Region-wide temporal and spatial architecture: is coral cover the whole story? Glob. Change Biol. 17 (7), 2470-2477.

Antoniadou, C., Chintiroglou, C., 2005. Biodiversity of zoobenthic hard-substrate sublittoral communities in the Eastern Mediterranean (North Aegean Sea). Estuar. Coast. Shelf S. 62, 637653.

Ar Gall, E., Le Duff, M., 2014. Development of a quality index to evaluate the structure of macroalgal communities. Estuar. Coast. Shelf S. 139, 99-109.

Balata, D., Piazzi, L., Cecchi, E., Cinelli, F., 2005. Variability of Mediterranean coralligenous assemblages subject to local variation in sediment deposition. Mar. Environ. Res. 60, 403-421.

Balata, D., Piazzi, L., Cinelli, F., 2007. Increase of sedimentation in a subtidal system: effects on the structure and diversity of macroalgal assemblages. J. Exp. Mar. Biol. Ecol. 351, 73-82.

Ballesteros, E., 1991a. Structure and dynamics of north-western Mediterranean marine communities: a conceptual model. Oecol. Aquat. 10, 223-242.

Ballesteros, E., 1991b. Seasonality of growth and production of a deep-water population of Halimeda tuna (Chlorophyceae, Caulerpales) in the north-western Mediterranean. Bot. Mar. 34, 291-301.

Ballesteros, E., 2006. Mediterranean coralligenous assemblages: a synthesis of present knowledge. Oceanogr. Mar. Biol. Annu. Rev. 44, 123-195.

Ballesteros, E., Sala, E., Garrabou, J., Zabala, M., 1998. Community structure and frond size distribution of a deep water stand of Cystoseira spinosa (Phaeophyta) in the northwestern Mediterranean. Eur. J. Phycol. 33, 121-128.

Ballesteros, E., Torras, X., Pinedo, S., García, M., Mangialajo, L., de Torres, M., 2007. A new methodology based on littoral community cartography dominated by macroalgae for the implementation of the European Water Framework Directive. Mar. Pollut. Bull. 55, 172-180.

Bianchi, C.N., Cattaneo-Vietti, R., Morri, C., Navone, A., Panzalis, P., Orrù, P., 2007. Coralligenous formations in the Marine Protected Area of Tavolara Punta Coda Cavallo (NE Sardinia, Italy). Biol. Mar. Medit. 14 (2), 148-149.

Bianchi, C.N., Parravicini, V., Montefalcone, M., Rovere, A., Morri, C., 2012. The challenge of managing marine biodiversity: a practical toolkit for a cartographic, territorial approach. Diversity 4, 419-452. 
Borja, A., Dauer, D. M., Grémare, A., 2012. The importance of setting targets and reference conditions in assessing marine ecosystem quality. Ecol. Indic. 12, 1-7.

Borja, A., Franco, J., Pérez, V., 2000. A marine biotic index to establish the ecological quality of softbottom benthos within European estuarine and coastal environments. Mar. Pollut. Bull. 40, 11001114.

Boudouresque, C.F., 1973. Recherches de bionomie analytique, structurale et expérimentale sur les peuplements benthiques sciaphiles de Méditerranée Occidentale (fraction algale). Les peuplements sciaphiles de mode relativement calme sur substrats durs. Bull. Mus. Hist. Nat. Marseille 33, $147-$ 225.

Boudouresque, C.F., 2004. Marine biodiversity in the Mediterranean: status of species, populations and communities. Sci. Rep. Port-Cros Natl. Park 20, 97-146.

Burgman, M.A., McBride, M., Ashton, R., Speirs-Bridge, A., Flander, L., Wintle, B., Fidler, F., Rumpff, L., Twardy, C., 2011. Expert status and performance. PLoS One 6, e22998.

Casellato, S., Stefanon, A., 2008. Coralligenous habitat in the northern Adriatic Sea: an overview. Mar. Ecol. 29, 321-341.

Cecchi, E., Piazzi, L., 2010. A new method for the assessment of the ecological status of coralligenous assemblages. Biol. Mar. Medit. 17 (1), 162-163.

Coma, R., Ribes, M., Serrano, E., Jiménez, E., Salat, J., Pascual, J., 2009. Global warming-enhanced stratification and mass mortality events in Mediterranean. PNAS 106 (15), 6176-6181.

Council European Communities, 1992. Council Directive 92/43/EEC of 21 May 1992 on the conservation of natural habitats and of wild fauna and flora. Off. J. EU, L206, 7-50.

Davies, C.E., Moss, D., Hill, M.O., 2004. EuNIS Habitat Classification revised 2004. Report to the European Topic Centre on Nature Protection and Biodiversity, European Environmental Agency, October 2004.

Deter, J., Descamp, P., Ballesta, L., Boissery, P., Holon, F., 2012. A preliminary study toward an index based on coralligenous assemblages for the ecological status assessment of Mediterranean French coastal waters. Ecol. Indic. 20, 345-352.

Di Franco, A., Milazzo, M., Baiata, P., Tomasello, A., Chemello, R., 2009. Scuba diver behaviour and its effects on the biota of a Mediterranean marine protected area. Environ. Conserv. 36 (1), 32-40.

Ferdeghini, F., Acunto, S., Cocito, S., Cinelli, F., 2000. Variability at different spatial scales of a coralligenous assemblage at Giannutri Island (Tuscan Archipelago, northwest Mediterranean). Hydrobiol. 440, 27-36.

Garrabou, J., Ballesteros, E., Zabala, M., 2002. Structure and dynamics of north-western Mediterranean benthic communities along a depth gradient. Estuar. Coast. Shelf S. 55, 493-508.

Garrabou, J., Coma, R., Bensoussan, N., Bally, M., Chevaldonné, P., Cigliano, M., Diaz, D., Harmelin, J.G., Gambi, M.C., Kersting, D.K., Ledoux, J.B., Lejeusne, C., Linares, C., Marschal, 
C., Pérez, T., Ribes, M., Romano, J.C., Serrano, E., Teixido, N., Torrents, O., Zabala, M., Zuberer, F., Cerrano, C., 2009. Mass mortality in Northwestern Mediterranean rocky benthic communities: effects of the 2003 heat wave. Glob. Change Biol. 15, 1090-1103.

Gatti, G., Montefalcone, M., Rovere, A., Parravicini, V., Morri, C., Albertelli, G., Bianchi, C.N., 2012. Sea-floor integrity down the harbor waterfront: the coralligenous shoals off Vado Ligure (NW Mediterranean). Adv. Oceanol. Limnol. 3(1), 51-67.

Gobert, S., Sartoretto, S., Rico-Raimondino, V., Andral, B., Chery, A., Lejeune, P., Boissery, P., 2009. Assessment of the ecological status of Mediterranean French coastal waters as required by the Water Framework Directive using Posidonia oceanica Rapid Easy Index: PREI. Mar. Pollut. Bull. $58,1727-1733$.

Guidetti, P., Terlizzi, A., Fraschetti, S., Boero, F., 2002. Spatio-temporal variability in fish assemblages associated with coralligenous formations in south eastern Apulia (SE Italy). It. J. Zool. 69 (4), 325-331.

Harmelin, J.G., 1990. Ichthyofauna of the Mediterranean rocky bottoms: Structure of the coralligenous ground assemblage of Port-Cros Island (National Park, France). MARSEILLE 50, 23-30.

Hobday, A.J., 2011. Sliding baselines and shuffling species: implications of climate change for marine conservation. Mar. Ecol. 32, 392-403.

Hodgson, G., 1999. A global assessment of human effects on coral reefs. Mar. Pollut. Bull. 38 (5), $345-355$.

Hong, J.S., 1982. Contribution à l'étude des peuplements d'un fond de concrétionnement coralligène dans la région marseillaise en Méditerranée Nord-occidentale. Bull. KORDI 4, $27-51$.

Hong, J.S., 1983. Impact of the pollution on the benthic community. Bull. Kor. Fish. Soc. 16 (3), 273290.

Jackson, J.B.C., Sala, E., 2001. Unnatural oceans. Sci. Mar. 65, 273-281.

Laborel, J., 1960. Contribution à l"étude directe des peuplements benthiques sciaphiles sur substrat rocheux en Méditerranée. Rec. Trav. Stat. Mar. Endoume 20 (33), 117-174.

Laborel, J., 1961. Le concrétionnement algal "coralligène" et son importance géomorphologique en Méditerranée. Rec. Trav. Stat. Mar. Endoume 23, 37-60.

Laubier, L., 1966. Le coralligène des Albères: monographie biocénotique. Ann. Inst. Océanogr. Monaco 43, 139-316.

Lloret, J., Marin, A., Marin-Guirao, L., Carreño, M.F., 2006. An alternative approach for managing scuba diving in small marine protected areas. Aquat. Conserv. 16, 579-591.

Lloret, J., Zaragoza, N., Caballero, D., Riera, V., 2008. Impacts of recreational boating on the marine environment of Cap de Creus (Mediterranean Sea). Ocean Coast. Manag. 51 (11), 749-754.

Lopez y Royo, C., Silvestri, C., Salivas-Decaux, M., Pergent, G., Casazza, G., 2009. Application of an angiosperm-based classification system (BiPo) to Mediterranean coastal waters: using spatial 
analysis and data on metal contamination of plants in identifying sources of pressure. Hydrobiol. 633, 169-179.

MacDonald, D.S., Little, M., Eno, N.C., Hiscock, K., 1996. Disturbance of benthic species by fishing activities: a sensitivity index. Aquat. Conserv. 6, 257-268.

McClanahan, T.R., Sala, E., 1997. A Mediterranean rocky-bottom ecosystem fisheries model. Ecol. Model. 104, 145-164.

Meese, R.J., Tomich, P.A., 1992. Dots on the rocks: a comparisons of percent cover estimation methods. J. Exp. Mar. Biol. Ecol. 165, 59-73.

Millot, C., 1990. The Gulf of Lions' hydrodynamics. Cont. Shelf Res.10 (9-11), 885-894.

Muxika, I., Borja, A., Bald, J., 2007. Using historical data, expert judgment and multivariate analysis in assessing reference conditions and benthic ecological status, according to the European Water Framework Directive. Mar. Pollut. Bull. 55, 16-29.

Orfanidis, S., Panayotidis, P., Stamatis, N., 2001. Ecological evaluation of transitional and coastal waters: A marine benthic macrophytes-based model. Med. Mar. Sci. 2, 45-65.

Pairaud, I., Gatti, J., Bensoussan, N., Verney, R., Garreau, P., 2011. Hydrology and circulation in a coastal area off Marseille: Validation of a nested 3D model with observations. J. Marine Syst. 88 (1), 20-33.

Parravicini, V., Micheli, F., Montefalcone, M., Morri, C., Villa, E., Castellano, M., Povero, P., Bianchi, C.N., 2013. Conserving biodiversity in a human-dominated world: degradation of marine sessile communities within a protected area with conflicting human uses. PLoS One 8 (10), e75767.

Parravicini, V., Micheli, F., Montefalcone, M., Villa, E., Morri, C., Bianchi, C.N., 2010. Rapid assessment of epibenthic communities: a comparison between two sampling techniques. J. Exp. Mar. Biol. Ecol. 395, 21-29

Parravicini, V., Morri, C., Ciribilli, G., Montefalcone, M., Albertelli, G., Bianchi, C.N., 2009. Size matters more than method: Visual quadrats vs photography in measuring human impact on Mediterranean rocky reef communities. Estuar. Coast. Shelf S. 81, 359-367.

Pérès, J., Picard, J.M., 1964. Nouveau manuel de bionomie benthique de la mer Méditerranée. Rec. Trav. Stat. Mar. Endoume 31 (47), 1-131.

Perez, T., Harmelin, J.G., Vacelet, J., Sartoretto, S., 2002. La bioévaluation de la qualité littorale par les peuplements de substrats durs: spongiaires, gorgonaires et bryozoaires comme indicateurs de pollution. Programme LITEAU, Rapport final, 44-70.

Piazzi, L., Balata, D., Pertusati, M., Cinelli, F., 2004. Spatial and temporal variability of Mediterranean macroalgal coralligenous assemblages in relation to habitat and substratum inclination. Bot. Mar. 47, 105-115. 
Piazzi, L., Pardi, G., Balata, D., Cecchi, E., Cinelli, F., 2002. Seasonal dynamics of a subtidal northwestern Mediterranean macroalgal community in relation to depth and substrate inclination. Bot. Mar. 45, 243-252.

Ponti, M., Fava, F., Abbiati, M., 2011a. Spatial-temporal variability of epibenthic assemblages on subtidal biogenic reefs in the northern Adriatic Sea. Mar. Biol. 158, 1447-1459.

Ponti, M., Perlini, R.A., Ventra, V., Grech, D., Previati, M., Huete Stauffer, C., Abbiati, M., Cerrano, C., 2011b. Effects of gorgonian forests on the recruitment of epibenthic species. Biol. Mar. Medit. $18(1), 89-92$.

Rice, J., Arvanitidis, C., Borja, A., Frid, C., Hiddink, J.G., Krause, J., Lorance, P., Ragnarsson, S.A., Sköld, M., Trabucco, B., Enserink, L., Norkko, A., 2012. Indicators of sea-floor integrity under the European Marine Strategy Framework Directive. Ecol. Indic. 12, 174-184.

Roghi, F., Parravicini, V., Montefalcone, M., Rovere, A., Morri, C., Peirano, A., Firpo, M., Bianchi, C.N., Salvati, E., 2010. Decadal evolution of a coralligenous ecosystem under the influence of human impacts and climate change. Biol. Mar. Medit. 17, 59-62.

Romero, J., Martínez-Crego, B., Alcoverro, T., Pérez, M., 2007. A multivariate index based on the seagrass Posidonia oceanica (POMI) to assess ecological status of coastal waters under the water framework directive (WFD). Mar. Pollut. Bull. 55, 196-204.

Ros, J., Olivella, I., Gili, J.M., 1984. Els sistemes naturals de les Illes Medes. Arxius Institut d'Estudis Catalans, Barcelona, Secció Ciències 73.

Ros, J., Romero, J., Ballesteros, E., Gili, J.M., 1985. Diving in blue water: the benthos, in: Margalef, R. (Ed.), Western Mediterranean. Pergamon, Oxford, pp. 233-295.

Rosenberg, R., Blomqvist, M., Nilsson, H.C., Cederwall, H., Dimming, A., 2004. Marine quality assessment by use of benthic species-abundance distributions: a proposed new protocol within the European Union Water Framework Directive. Mar. Pollut. Bull. 49, 728-739.

Sala, E., Ballesteros, E., Dendrinos, P., Di Franco, A., Ferretti, F., Foley, D., Fraschetti, S., Friedlander, A., Garrabou, J., Güçlüsoy, H., Guidetti, P., Halpern, B. S., Hereu, B., Karamanlidis, A. A., Kizikaya, Z., Macpherson, E., Mangialajo, L., Mariani, S., Micheli, F., Pais, A., Riser, K., Rosenberg, A. A., Sales, M., Selkoe, K. A., Starr, R., Tomas, F., Zabale, M., 2012. The structure of Mediterranean rocky reef ecosystems across environmental and human gradients, and conservation implications. PLoS One 7 (2), e32742.

Salomidi, M., Katsanevakis, S., Borja, Á., Braeckman, U., Damalas, D., Galparsoro, I., Mifsud, R., Mirto, S., Pascual, M., Pipitone, C., Rabaut, M., Todorova, V., Vassilopoulou, V., Vega Fernández, T., 2012. Assessment of goods and services, vulnerability, and conservation status of European seabed biotopes: a stepping stone towards ecosystem-based spatial management. Med. Mar. Sci. 13 (1), 49-88. 
Sarà, M., 1969. Research on coralligenous formations: problems and perspectives. Pubbl. Stn. Zool. Napoli I Mar. Ecol. 37, 124-134.

Sekovski, I., Newton, A., Dennison, W.C., 2012. Megacities in the coastal zone: using a driverpressure-state-impact-response framework to address complex environmental problems. Estuar. Coast. Shelf S. 96, 48-59.

Simboura, N., Zenetos, A., 2002. Benthic indicators to use in Ecological Quality classification of Mediterranean soft bottom marine ecosystems, including a new Biotic Index. Med. Mar. Sci. 3, $77-$ 111.

Spanier, E., Pisanty, S., Tom M., Almog-Shtayer, G., 1989. The fish assemblage on a coralligenous shallow shelf off the Mediterranean coast of northern Israel. J. Fish Biol. 35 (5), 641-649.

Stachowitsch, M., 2003. Research on intact marine ecosystems: a lost era. Mar. Pollut. Bull. 46 (7), 801-805.

Tamburello, L., Benedetti-Cecchi, L., Ghedini, G., Alestra, T., Bulleri, F., 2012. Variation in the structure of subtidal landscapes in the NW Mediterranean Sea. Mar. Ecol. Prog. Ser. 457, 29-41.

Thompson, A.A., Mapstone, B.D., 1997. Observer effect and training in underwater visual surveys of reef fishes. Mar. Ecol. Prog. Ser. 154, 53-63.

UNEP-MAP-RAC/SPA, 2008. Action plan for the conservation of the coralligenous and other calcareous bio-concretions in the Mediterranean Sea, ed. RAC/SPA, Tunis.

Virgilio, M., Airoldi, L., Abbiati, M., 2006. Spatial and temporal variations of assemblages in a Mediterranean coralligenous reef and relationships with surface orientation. Coral Reefs 25, 265272.

Wernberg, T., Smale, D.A., Tuya, F., Thomsen, M.S., Langlois, T.J., de Bettignies, T., Bennett, S., Rousseaux, C., 2012. An extreme climatic event alters marine ecosystem structure in a global biodiversity hotspot. Nat. Clim. Change 3, 78-82. 
1 Table 1. Data collected for each replicate. In the bionomic characterization, the height of organisms

2 composing each layer is reminded.

3

\begin{tabular}{|c|c|}
\hline \multicolumn{2}{|c|}{ Geomorphologic characterization } \\
\hline Morphotypes & Shoal/outcrop/cliff/landslide deposits/detritic \\
\hline \multicolumn{2}{|c|}{ Mesologic characterization } \\
\hline Physical features & Depth, slope, exposure, elevation from the bottom \\
\hline \multicolumn{2}{|c|}{ Bionomic characterization } \\
\hline $\begin{array}{l}\text { Basal layer } \\
<1 \mathrm{~cm} \text { height }\end{array}$ & $\begin{array}{l}\text { - Percent cover of benthic categories (BCs), i.e.: encrusting } \\
\text { calcified rhodophyta (ECR), non-calcified encrusting } \\
\text { algae (NCEA), encrusting animals (EA), turf-forming } \\
\text { algae (TURF), sediment (SED) } \\
\text { - Semi-quantitative abundance of boring species } \\
\text { - } \\
\text { Thickness and consistency of calcareous layer }\end{array}$ \\
\hline $\begin{array}{l}\text { Intermediate layer } \\
1 \text { to } 10 \mathrm{~cm} \text { height }\end{array}$ & $\begin{array}{l}-\quad \text { List of species } \\
-\quad 6 \text { random photographs without frame }\end{array}$ \\
\hline $\begin{array}{l}\text { Upper layer } \\
>10 \mathrm{~cm} \text { height }\end{array}$ & $\begin{array}{l}\text { - } \quad \text { Visual estimation of percent cover of each species } \\
-\quad \text { Maximum height of each species } \\
\text { - } \quad \text { Percentage of necrosis (also if covered by epibiosis) }\end{array}$ \\
\hline
\end{tabular}


1 Table 2. Criteria for the assignation of quality scores to each descriptor, for each replicate.

2

\begin{tabular}{l|l}
\hline \multicolumn{2}{c}{ BASAL LAYER } \\
\hline \multirow{3}{*}{ Percent cover of BCs } & 1: TURF/SED \\
& 2: NCEA, AN \\
& 3: ECR \\
\hline \multirow{3}{*}{ Thickness and consistency of calcareous layer } & 1: null penetration \\
& 2: penetration $>1 \mathrm{~cm}$ \\
& $3:$ penetration up to $1 \mathrm{~cm}$ \\
\hline \multirow{3}{*}{ Borer marks } & 1: common \\
& 2: occasional \\
& $3:$ absent \\
\hline
\end{tabular}

\section{INTERMEDIATE LAYER}

\begin{tabular}{l|l}
\hline & $1: \mathrm{SR}<5$ \\
Specific Richness (SR) & $2: 5 \leq \mathrm{SR} \leq 8$ \\
& $3: \mathrm{SR}>8$ \\
\hline \multirow{3}{*}{ Erect Calcified Organisms (ECO) } & $1: \mathrm{ECO} \leq 1$ \\
& $2: 1<\mathrm{ECO} \leq 3$ \\
& $3: \mathrm{ECO}>3$ \\
\hline \multirow{3}{*}{ Sensitivity of bryozoans } & $1:$ Myriapora truncata \\
& $2:$ Pentapora fascialis, \\
& Adeonella calveti \\
& $3:$ Smittina cervicornis, \\
& Reteporella grimaldii \\
\hline
\end{tabular}

\section{UPPER LAYER}

\begin{tabular}{l|l}
\hline & $1:$ cover $<5 \%$ \\
Total cover of species & $2: 5 \% \leq$ cover $\leq 25 \%$ \\
& $3:$ cover $>25 \%$ \\
\hline \multirow{3}{*}{ Maximum height $(\mathrm{MH})$} & $1: \mathrm{MH}<0.3 \mathrm{LMH}^{\mathrm{a}}$ \\
& $2: 0.3 \mathrm{LMH} \leq \mathrm{MH} \leq 0.6 \mathrm{LMH}$ \\
& $3: \mathrm{MH}>0.6 \mathrm{LMH}$ \\
\hline Necrosis $(\mathrm{N})$ & $1: \mathrm{N}>75 \%$ \\
& $2: 10 \% \leq \mathrm{N} \leq 75 \%$ \\
& $3: \mathrm{N}<10 \%$ \\
\hline
\end{tabular}

3

$4 \quad{ }^{a}$ Literature Maximum Height, the maximum height find in literature for each species. 
1 Table 3. Geomorphological, mesological and bionomic characterization of sampling stations.

2

\begin{tabular}{|c|c|c|c|c|c|c|c|}
\hline & & Geomorphology & & Mess & ogy & & Bionomy \\
\hline Code & Site & Morphotype & $\begin{array}{c}\text { Depth } \\
\text { (m) }\end{array}$ & $\begin{array}{c}\text { Elevation } \\
(\mathbf{m})\end{array}$ & $\begin{array}{c}\text { Slope } \\
\left({ }^{\circ}\right)\end{array}$ & $\begin{array}{c}\text { Exposure } \\
\left({ }^{\circ} \mathbf{N}\right)\end{array}$ & Habitat type (EuNIS Code) \\
\hline 1 & Méjean & Steep cliff & 32.5 & 1.9 & 95 & 180 & $\begin{array}{l}\text { Facies with Eunicella cavolini } \\
\text { (A4.269) }\end{array}$ \\
\hline 2 & Large Niolon & Outcrop & 34.5 & 1.6 & 70 & 240 & Facies of impoverishment \\
\hline 3 & Tiboulen & Steep cliff & 28.7 & 6.6 & 70 & 60 & $\begin{array}{l}\text { Facies with Paramuricea clavata } \\
\text { (A4.26B) }\end{array}$ \\
\hline 4 & Ile du Planier & Steep cliff & 34.3 & 3.7 & 100 & 300 & $\begin{array}{l}\text { Facies with Paramuricea clavata } \\
\text { and Eunicella cavolini (A4.26B, } \\
\text { A4.269) }\end{array}$ \\
\hline 5 & Cap Caveau & Steep cliff & 34.7 & 5.6 & 80 & 160 & $\begin{array}{l}\text { Facies with Paramuricea clavata } \\
\text { and Eunicella cavolini (A4.26B, } \\
\text { A4.269) }\end{array}$ \\
\hline 6 & Fromages & $\begin{array}{l}\text { Low inclination } \\
\text { platform }\end{array}$ & 33.1 & 0.8 & 30 & 170 & $\begin{array}{l}\text { Facies with Paramuricea clavata } \\
\text { (A4.26B) }\end{array}$ \\
\hline 7 & Moyade & Steep cliff & 33.4 & 3.0 & 85 & 130 & $\begin{array}{l}\text { Facies with Paramuricea clavata } \\
\text { (A4.26B) }\end{array}$ \\
\hline 8 & Ile Plane Nord & $\begin{array}{l}\text { Low inclination } \\
\text { platform }\end{array}$ & 32.3 & 1.8 & 40 & 335 & Facies of impoverishment \\
\hline 9 & Imperial du Milieu & Steep cliff & 32.8 & 1.5 & 110 & 260 & $\begin{array}{l}\text { Facies with Paramuricea clavata } \\
\text { and Eunicella cavolini (A4.26B, } \\
\text { A4.269) }\end{array}$ \\
\hline 10 & Ile Plane South & Steep cliff & 30.0 & 1.9 & 95 & 180 & $\begin{array}{l}\text { Facies with Paramuricea clavata } \\
\text { (A4.26B) }\end{array}$ \\
\hline 11 & Morgiou & Steep cliff & 34.1 & 10.4 & 60 & 150 & $\begin{array}{l}\text { Facies with Paramuricea clavata } \\
\text { and Eunicella cavolini (A4.26B, } \\
\text { A4.269) }\end{array}$ \\
\hline 12 & Figuerolle & Outcrop & 26.4 & 2.1 & 30 & 200 & $\begin{array}{l}\text { Association with Halimeda tuna } \\
\text { and Codium bursa }\end{array}$ \\
\hline 13 & Bec de l'eAigle West & Steep cliff & 32.2 & 1.7 & 60 & 225 & $\begin{array}{l}\text { Facies with Eunicella cavolini } \\
\text { (A4.269) }\end{array}$ \\
\hline 14 & Bec de $1^{e}$ Aigle East & Steep cliff & 34.9 & 5.3 & 60 & 130 & $\begin{array}{l}\text { Facies with Paramuricea clavata } \\
\text { and Eunicella cavolini (A4.26B, } \\
\text { A4.269) }\end{array}$ \\
\hline 15 & Les Rosiers & Outcrop & 33.8 & 6.7 & 75 & 230 & $\begin{array}{l}\text { Association with Flabellia } \\
\text { petiolata and Peyssonnelia } \\
\text { squamaria (A3.23J) }\end{array}$ \\
\hline 16 & Pierre du Levant & Steep cliff & 39.4 & 3.3 & 40 & 60 & $\begin{array}{l}\text { Facies with Paramuricea clavata } \\
\text { and Eunicella cavolini (A4.26B, } \\
\text { A4.269) }\end{array}$ \\
\hline 17 & $\begin{array}{l}\text { Sêche des Pêcheurs } \\
\text { West }\end{array}$ & Outcrop & 31.8 & 1.0 & 60 & 230 & $\begin{array}{l}\text { Association with Flabellia } \\
\text { petiolata, Halimeda tuna and } \\
\text { Codium coralloides }\end{array}$ \\
\hline 18 & $\begin{array}{l}\text { Sêche des Pêcheurs } \\
\text { East }\end{array}$ & Outcrop & 28.9 & 2.6 & 90 & 335 & $\begin{array}{l}\text { Facies with Paramuricea clavata } \\
\text { (A4.26B) }\end{array}$ \\
\hline 19 & Les Deux Frères & Steep cliff & 31.4 & 2.0 & 80 & 130 & $\begin{array}{l}\text { Facies with Paramuricea clavata } \\
\text { and Eunicella cavolini (A4.26B, } \\
\text { A4.269) }\end{array}$ \\
\hline 20 & Large Oursinière & Outcrop & 33.3 & 0.9 & 45 & 225 & $\begin{array}{l}\text { Association with Flabellia } \\
\text { petiolata and turf }\end{array}$ \\
\hline 21 & Formigue & $\begin{array}{l}\text { Low inclination } \\
\text { platform }\end{array}$ & 32.2 & 5.1 & 40 & 180 & $\begin{array}{l}\text { Facies with Paramuricea clavata } \\
\text { and Eunicella cavolini (A4.26B, } \\
\text { A4.269) }\end{array}$ \\
\hline
\end{tabular}


1 Table 4. Results of paired Student's $t$ tests on univariate measurements and counts by $\mathrm{O}_{1}$ and $\mathrm{O}_{2}$.

2

\begin{tabular}{lcc}
\hline & $\boldsymbol{t}$ & $\mathbf{p}$ \\
\hline Basal layer & & \\
Penetrometry & -1.452 & 0.085 \\
Borer marks & -1.000 & 0.136 \\
Intermediate layer & & \\
Nr of species & 2.001 & 0.085 \\
Upper layer & & \\
Total cover & -1.721 & 0.136 \\
Max height & -2.097 & 0.081 \\
Necrosis & -1.410 & 0.208 \\
\hline
\end{tabular}

3

4

5 


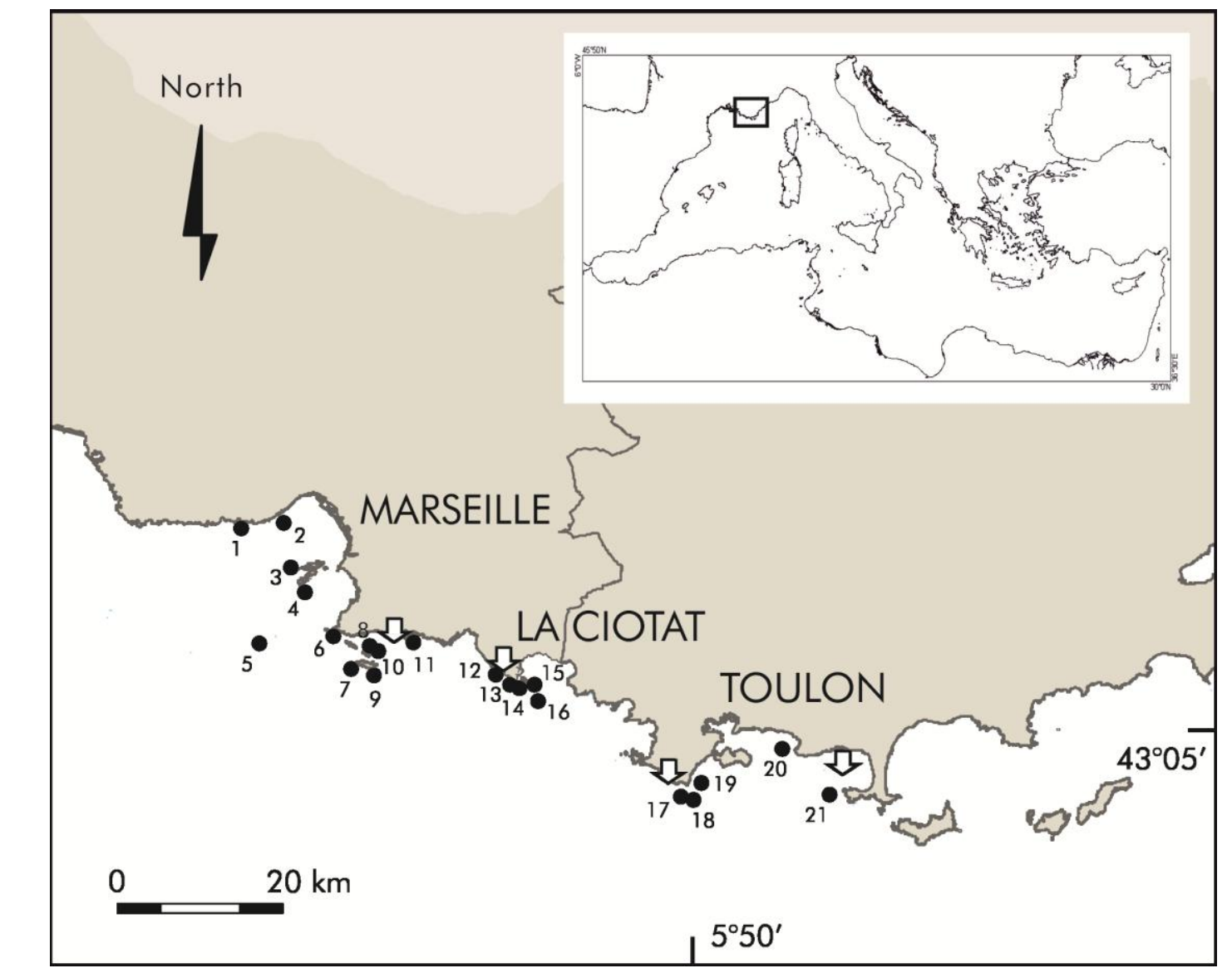

2 Figure 1. Study area and sampling stations, represented by numbers as in Table 3. White arrows 3 indicate the position of sewage treatment stations outfalls; from west to east: Cortiou (Marseille), $4 \quad$ Figuerolle (La Ciotat), Cap Cicié (Toulon west), Pont de la Clue (Toulon east). 

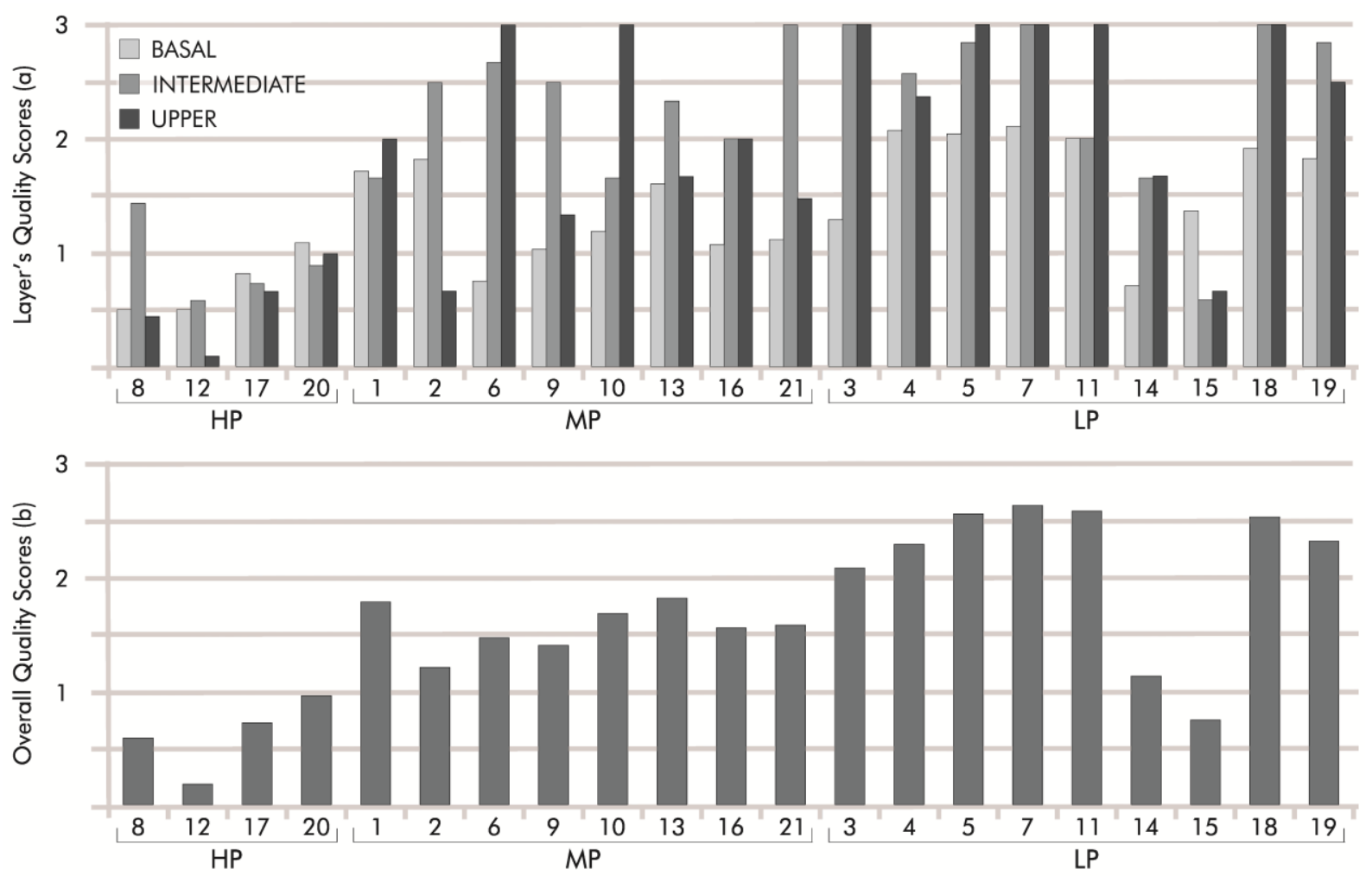

Figure 2. Layer's quality scores (a) and overall quality scores (b) for each station. Stations are grouped 3 according to the level of pressure they are subjected to: HP $=$ High Pressure, $\mathrm{MP}=$ Moderate Pressure, $4 \quad \mathrm{LP}=$ Low Pressure.

5 


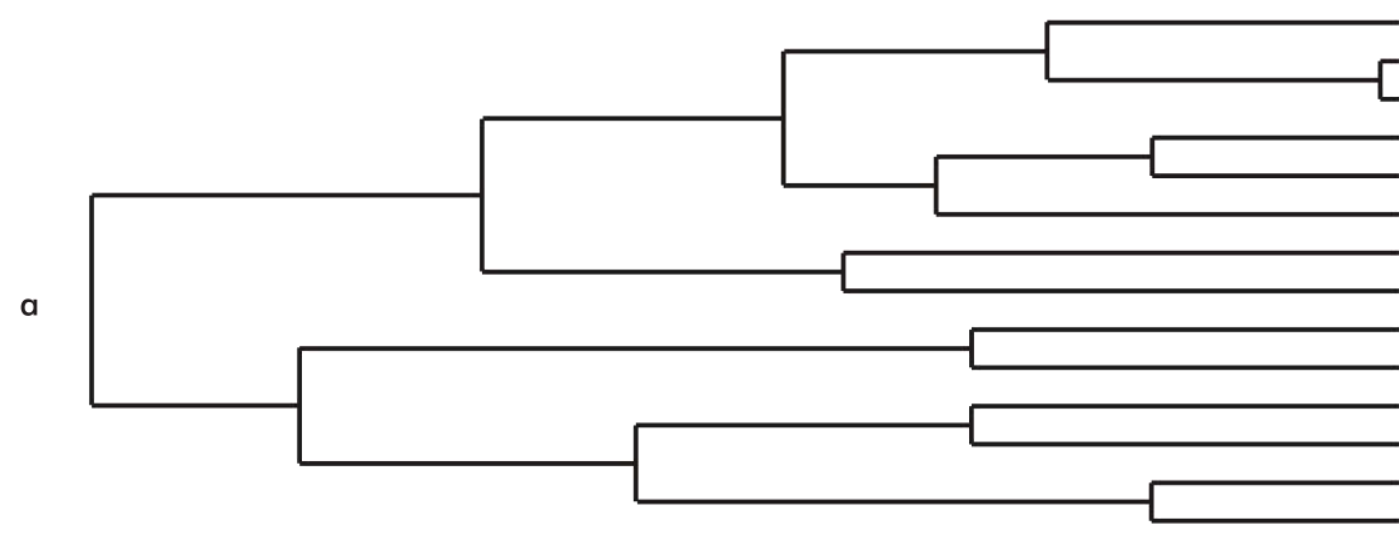

$6-0 x$

$10-0 x$ $10-P$

$6-P$

$1-O x$

$1-P$

2 - Ox

2 - $P$

$11-O x$

$11-P$

$13-0 x$

$13-\mathrm{P}$

$19-P$

19 - Ox

b
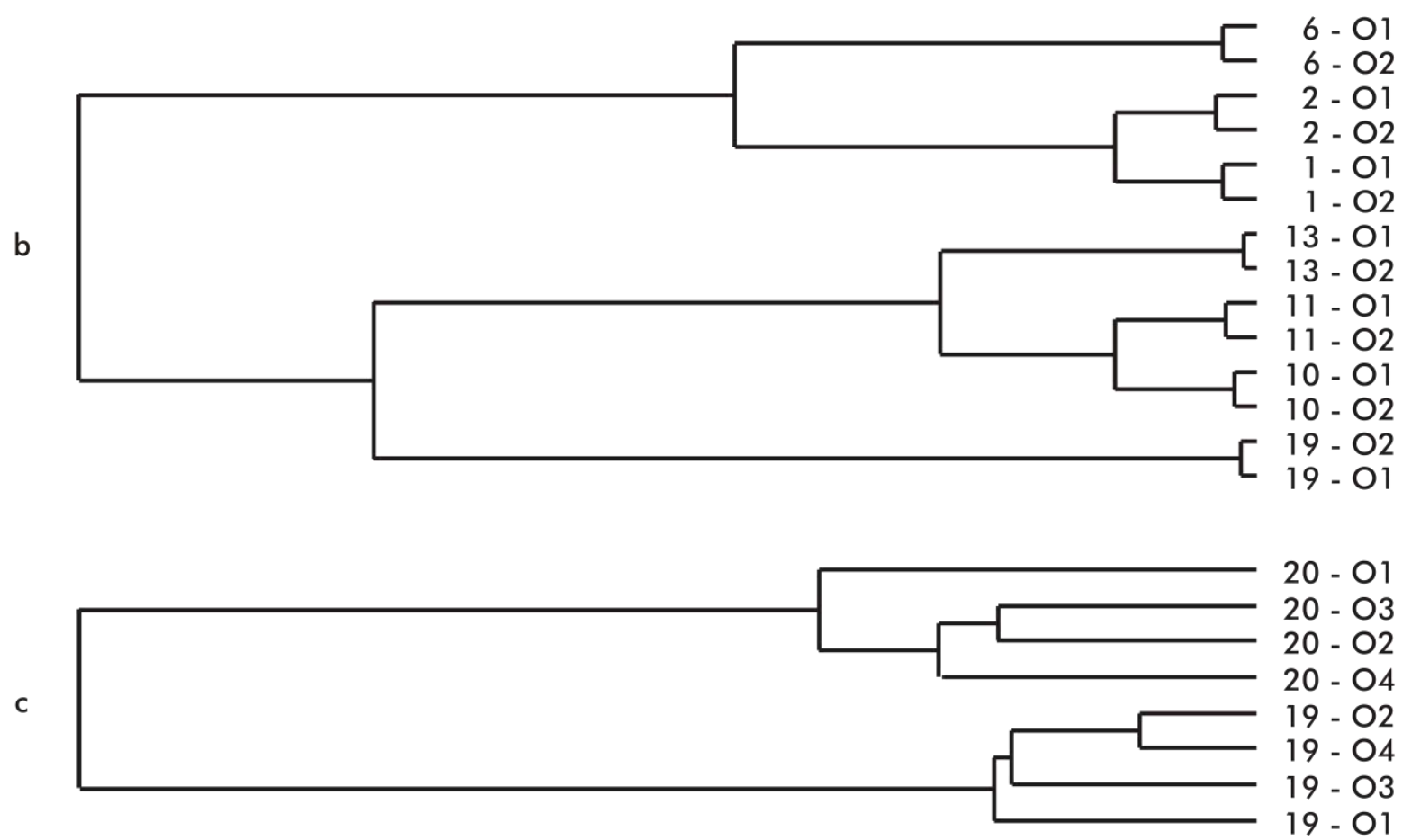

1

Figure 3. Comparisons of substrate cover estimates by visual surveys in situ and through photographs:

3 a) average observer $\left(\mathrm{O}_{\mathrm{x}}\right)$ vs. photography $(\mathrm{P})$; b) two expert observers $\left(\mathrm{O}_{1}\right.$ and $\left.\mathrm{O}_{2}\right)$; c) expert $\left(\mathrm{O}_{1}\right.$ and

$\left.4 \quad \mathrm{O}_{2}\right)$ vs. non-expert observers $\left(\mathrm{O}_{3}\right.$ and $\left.\mathrm{O}_{4}\right)$. Numbers refer to stations. 